\title{
Comparing Nurses' and Head Nurses' Perspectives on the Factors Behind the Quality of Nursing Documentation
}

\author{
Mahnaz Shahverdi ${ }^{1}$ and Ahmad Nasiri (iD) ${ }^{2,{ }^{*}}$ \\ ${ }^{1}$ MSC Student of Nursing, Faculty of Nursing, Birjand University of Medical Sciences, Birjand, Iran \\ ${ }^{2}$ Associate Professor, Faculty of Nursing and Midwifery, Birjand University of Medical Sciences, Birjand, Iran \\ "Corresponding author: Associate Professor, Medical Toxicology and Drug Abuse Research Center, Birjand University of Medical Sciences, Birjand, Iran. Email: \\ nasiri2006@bums.ac.ir
}

Received 2018 August 28; Revised 2018 November 19; Accepted 2018 December 01.

\begin{abstract}
Background: Nursing documentation has significant roles in giving coherence to teamwork, making effective use of healthcare providers' knowledge, improving care quality, maintaining care continuity, and identifying changes in patients' conditions. However, studies show its poor quality.

Objectives: This study compared nurses' and head nurses' perspectives on the factors behind the quality of nursing documentation.

Methods: This descriptive-correlational study was conducted in 2017 in Valiasr (PBUH) Hospital, Birjand, Iran. Accordingly, 140 eligible nurses and all 15 head-nurses in the hospital were recruited to the study through simple random sampling and census, respectively. They filled out a researcher-made 26-item questionnaire about factors behind the quality of nursing documentation. Because of the non-normal distribution of the study variables, the Mann-Whitney U, Kruskal-Wallis, and Friedman tests were used for data analysis. The level of significance was set at less than 0.05 .

Results: Head nurses did not significantly differ from nurses respecting the mean scores of personal, managerial, and organizational factors behind the documentation quality $(\mathrm{P}>0.05)$. The highest-scored factors were organizational factors.

Conclusions: Organizational factors are the most important factors behind the quality of nursing documentation. Thus, adequate nurse staffing and avoidance from assigning non-nursing responsibilities to nurses are recommended to improve the quality of nursing documentation.
\end{abstract}

Keywords: Nursing Documentation, Nurses, Perspectives, Care Quality

\section{Background}

Nursing documentation is a useful framework for presenting and evaluating nursing care (1). It is a set of written information about care services provided to patients and is an important tool to evaluate and verify the accuracy of healthcare services and to support patient and nurse rights (2). It is also used to determine healthcare costs, patients' educational needs, and discharge plan and is considered as the main source of reliable patient data, a reminder tool for nurses, and a base for identifying patient problems (3-7). The documentation gives coherence to teamwork, helps make use of other staff's professional knowledge, improves care quality, ensures care continuity, enables nurses to execute care plans effectively, and helps them to identify changes in patients' conditions quickly (8).

Despite the importance of nursing documentation, evidence shows problems in its performance. For instance, a study reported that $50 \%$ of nursing documentation is of poor quality. The same study also reported that nurses considered documentation as an unnecessary paperwork that just increases their workload (9). Another study showed that one out of every four cases of professional negligence in patient care is related to documentation errors (10). Poor nursing documentation can cause different negative consequences for patients, nurses, and healthcare systems. For instance, ambiguous or untimely documentation, improper correction of documentation errors, or documentation of personal views instead of actual care delivered to patients can cause legal problems for nurses. Pitfalls in nursing documentation may also be used to confirm nurses' malpractice (11).

Different studies assessed factors behind poor nursing documentation. A qualitative study on 20 nurses and 30 patient medical records found that factors such as the heavy workload, the insignificant effects of proper documentation on nurses' career advancement, and the higher importance and priority of care provision com-

Copyright (c) 2018, Modern Care Journal. This is an open-access article distributed under the terms of the Creative Commons Attribution-NonCommercial 4.0 International License (http://creativecommons.org/licenses/by-nc/4.0/) which permits copy and redistribute the material just in noncommercial usages, provided the original work is properly cited. 
pared to documentation could negatively affect documentation quality (1). Two other studies reported that factors behind poor nursing documentation were nurses' limited self-confidence, poor writing skills, attitudes towards documentation (12), low nurse-to-patient ratio, heavy workload, fatigue, insignificant effect of documentation on nurses' career advancement, higher priority of care, job dissatisfaction, and lack of knowledge about the principles of quality documentation and the negative legal consequences of poor documentation (10).

Our extensive literature search revealed that no study had yet evaluated factors behind nursing documentation from the perspective of nurses and head nurses. However, there were studies into the barriers of using nursing diagnosis and nursing process. For instance, a study reported that the main barriers to the documentation of nursing diagnoses were managerial and executive factors from nurses' perspectives and organizational factors from nursing managers' perspectives (13). Other studies found personal, managerial, and organizational factors as barriers to the use of the nursing process $(14,15)$. Coordination and collaboration between nurses (as staff who perform documentation) and nursing managers (as documentationrelated decision-makers) may help improve the quality of nursing documentation. A key prerequisite for such coordination and collaboration is to compare their perspectives in this area.

\section{Objectives}

The present study was conducted to compare nurses' and head nurses' perspectives on the factors behind the quality of nursing documentation.

\section{Methods}

This descriptive-analytical study was conducted in 2017 in Valiasr (PBUH) Hospital, Birjand, Iran. For sampling, a list was initially created of all nurses and head-nurses in the hospital. Then, 140 eligible nurses and all 15 headnurses in the hospital were recruited to the study through simple random sampling and census, respectively. The number of nurses to be recruited from each hospital ward was determined based on the sample size of the study and the total number of nurses in that ward. The inclusion criteria were clinical work experience of more than one year and willingness to participate in the study. Participants who voluntarily withdrew from the study were excluded. The sample size was calculated using the Cochran formula (i.e. $n=Z^{2} p q / d^{2}$ ) and the results of an earlier study that reported the low nurse-to-patient ratio as a major factor behind poor documentation, with a relative frequency of $90 \%$ (10). Thus, with a d of 0.05 and a confidence level of 0.90 , the sample size was estimated to be 138 .
The data collection tool was a researcher-made 26-item questionnaire with three main domains of personal factors (13 items), managerial factors (5 items), and organizational factors (eight items). The item scoring was done on a five-point scale from 1 ("Very little") to 5 ("Very much"). The total score of each domain was calculated by dividing the sum of its item scores by the number of its items, resulting in a score of 1 - 5 for each domain. The content validity of the questionnaire was evaluated and confirmed by six faculty members of the Birjand Faculty of Nursing and Midwifery, Birjand, Iran. For reliability assessment, 10 nurses were recruited to fill out the questionnaire and then, the Cronbach's alpha values of the questionnaire and its personal, managerial, and organizational factors were calculated to be $0.93,0.92,0.76$, and 0.71 , respectively. For data collection, we referred to the study setting, recruited eligible participants, and asked them to fill out the questionnaire in our presence within 30 minutes.

Data were analyzed via the SPSS program (V. 16.0). The Kolmogorov-Smirnov test indicated that the study variables did not have a normal distribution. Therefore, data analysis was conducted using Mann-Whitney U, Friedman, and Wilcoxon signed-rank tests at a significance level of less than 0.05 .

The Institutional Review Board and the Ethics Committee of Birjand Faculty of Nursing and Midwifery, Birjand, Iran, approved this study (with the codes of 4587 and IR.BUMS.REC.13960221, respectively). The participants were provided with explanations about the aim of the study and the anonymity of data collection and reporting.

\section{Results}

Among 140 recruited nurses, nine did not completely fill out their questionnaires and hence, the final data analysis was conducted on the data retrieved from 15 head nurses and 131 nurses. The head nurses were mostly females (93.3\%), held bachelor's degrees (86.7\%), and had a work experience of more than 15 years (73.3\%) and all of them were married and secured permanent official employment. As Table 1 shows, the most participating nurses were also females (89.3\%), married (86.3\%), and held bachelor's degrees (90.8\%).

Among personal factors, the highest mean scores were related to the items of time limitation during a work shift, assigning a higher priority to care provision rather than documentation, and work-related fatigue while the lowest scores were related to the items of assigning limited importance to documentation and low self-confidence in the documentation. The highest scores in the organizational factors domain were related to the items of nurses' heavy paperwork, assignment of non-nursing responsibilities to nurses, and heavy workload while the lowest mean 


\begin{tabular}{|c|c|c|}
\hline Characteristics & $\mathbf{N}$ & $\%$ \\
\hline \multicolumn{3}{|l|}{ Gender } \\
\hline Male & 14 & 10.7 \\
\hline Female & 117 & 89.2 \\
\hline \multicolumn{3}{|l|}{ Age, $y$} \\
\hline$\leq 30$ & 62 & 47.3 \\
\hline $31-40$ & 45 & 34.4 \\
\hline$>40$ & 24 & 18.3 \\
\hline \multicolumn{3}{|l|}{ Marital status } \\
\hline Single & 18 & 13.7 \\
\hline Married & 113 & 86.3 \\
\hline \multicolumn{3}{|l|}{ Academic degree } \\
\hline Associate & 6 & 4.6 \\
\hline Bachelor's & 119 & 90.8 \\
\hline Master's & 6 & 4.6 \\
\hline \multicolumn{3}{|l|}{ Work experience, y } \\
\hline$\leq 5$ & 56 & 42.7 \\
\hline $6-15$ & 40 & 30.5 \\
\hline$>15$ & 35 & 26.7 \\
\hline \multicolumn{3}{|l|}{ Employment status } \\
\hline Under a contract & 21 & 16 \\
\hline Permanent official & 59 & 45 \\
\hline Conditional official & 30 & 22.9 \\
\hline $\begin{array}{l}\text { Post-graduation } \\
\text { service }\end{array}$ & 21 & 16 \\
\hline
\end{tabular}

score was related to the item of fear of the negative consequences of precise documentation. Finally, the highestscored managerial factors were low nurse-to-patient ratio and the insignificant effects of proper documentation on nurses' career advancement while the lowest-scored items in this domain were the inefficient labor division and inadequate supervision of nursing documentation (Table 2).

Comparison between nurses and head nurses revealed no significant difference between them respecting their perspectives on factors behind the quality of nursing documentation $(P>0.05$; Table 3$)$. The highest- and the lowestscored domains among both nurses and head nurses were organizational and personal factors, respectively. The Friedman test revealed no statistically significant difference within the head nurse group and at least one statistically significant difference within the nurse group respecting the mean scores of the personal, managerial, and organizational factors (P value $=0.28$ and $<0.001)$. The Post hoc analysis using Wilcoxon signed-rank test indicated that in the nurse group, the mean scores of organi- zational and managerial factors were respectively greater than the mean scores of managerial and personal factors $(\mathrm{P}<0.0001$; Table 3$)$.

\section{Discussion}

The present study aimed to compare nurses' and head nurses' perspectives on the factors behind the quality of nursing documentation. The findings revealed that organizational factors were the most important factors in this area. The most important organizational factors were the assignment of non-nursing responsibilities to nurses and their heavy workload while the most important personal factors were time limitation during work shift, assigning higher priority to care provision rather than documentation, and work-related fatigue and the most important managerial factors were low nurse-to-patient ratio and insignificant effects of proper documentation on nurses' career advancement. In line with these findings, previous studies reported that the most important factors affecting documentation quality were the lengthiness of documentation, ineffective reward and punishment system (16), time limitation $(17,18)$, insignificant effects of proper documentation on nurses' career advancement, $(10,16)$, low nurse-to-patient ratio, heavy workload $(1,10,18,19)$, higher priority of care compared to documentation, unfamiliarity with technical terms and documentation principles $(10,18)$, lack of appropriate place for documentation, heavy documentation load, and inefficient quality control (18). Another study also reported that the most important barriers to the documentation of nursing diagnoses were managerial factors from nurses' perspectives and organizational factors from nursing managers' perspectives (13).

Quality care delivery and proper maintenance of care continuity largely depend on accurate information exchange among healthcare professionals in different work shifts, which is determined by proper and quality nursing documentation $(14,20,21)$. Accordingly, the accurate information exchange, shift report, and documentation are considered among the heaviest and most important responsibilities of nurses. Any documentation error or negligence can cause nurses' different professional and legal problems (21).

\subsection{Conclusion}

Organizational factors are the most important factors behind the quality of nursing documentation. Thus, appropriate and adequate nurse staffing and avoidance from assigning non-nursing responsibilities to nurses are recommended to improve the quality of nursing documentation. 
Table 2. The Mean Scores of Factors Behind the Quality of Nursing Documentation

\begin{tabular}{|c|c|c|}
\hline Factors & Head Nurses & Nurses \\
\hline \multicolumn{3}{|l|}{ Personal } \\
\hline Low self-confidence in nursing documentation & $2.87 \pm 1.41$ & $3.15 \pm 1.28$ \\
\hline Poor documentation skills & $3.07 \pm 1.34$ & $3.47 \pm 1.32$ \\
\hline Unfamiliarity with the principles of documentation & $3.47 \pm 1.41$ & $3.60 \pm 1.32$ \\
\hline Work-related fatigue & $3.60 \pm 1.45$ & $3.85 \pm 0.97$ \\
\hline Job dissatisfaction & $3.47 \pm 1.46$ & $3.36 \pm 1.17$ \\
\hline Time limitation during the work shift & $4.60 \pm 0.63$ & $3.96 \pm 0.96$ \\
\hline Poor job motivation & $3.20 \pm 1.42$ & $3.25 \pm 1.12$ \\
\hline Lack of knowledge about the legal consequences of incomplete documentation & $3.27 \pm 1.53$ & $3.67 \pm 1.15$ \\
\hline Assigning a higher priority to care provision than to care documentation & $4.07 \pm 1.03$ & $4.00 \pm 0.80$ \\
\hline Following routine documentation by novice nurses & $4.40 \pm 0.74$ & $3.72 \pm 0.90$ \\
\hline Illegibility of nursing documentation & $3.33 \pm 1.23$ & $3.35 \pm 1.04$ \\
\hline Limited importance of nursing documentation for nurses & $2.93 \pm 1.10$ & $2.92 \pm 1.30$ \\
\hline Nurses' lack of knowledge about different documentation styles & $3.07 \pm 1.03$ & $3.31 \pm 1.19$ \\
\hline \multicolumn{3}{|l|}{ Organizational } \\
\hline Authorities' attention to nursing documentation & $4.07 \pm 0.70$ & $3.69 \pm 0.84$ \\
\hline Heavy workload & $4.33 \pm 1.05$ & $4.46 \pm 0.65$ \\
\hline Clear guidelines for nursing documentation & $3.73 \pm 1.16$ & $3.71 \pm 0.93$ \\
\hline Nurses' heavy paperwork & $4.40 \pm 1.06$ & $4.48 \pm 0.64$ \\
\hline Assignment of non-nursing responsibilities to nurses & $4.53 \pm 0.83$ & $4.44 \pm 0.85$ \\
\hline Lack of managerial positive feedbacks to precise nursing documentation & $3.80 \pm 1.42$ & $3.91 \pm 1.02$ \\
\hline Fear of the negative consequences of precise documentation & $3.20 \pm 1.27$ & $3.53 \pm 1.13$ \\
\hline Physicians' inattention and lack of positive feedbacks to precise nursing documentation & $4.00 \pm 1.31$ & $3.76 \pm 1.03$ \\
\hline \multicolumn{3}{|l|}{ Managerial } \\
\hline Inefficient labor division & $3.73 \pm 1.34$ & $3.33 \pm 1.08$ \\
\hline Inadequate supervision of nursing documentation & $3.47 \pm 1.13$ & $3.34 \pm 1.03$ \\
\hline Low nurse-to-patient ratio & $4.20 \pm 1.21$ & $4.40 \pm 0.80$ \\
\hline Lack of timely feedbacks from executive managers & $3.60 \pm 1.24$ & $3.58 \pm 0.98$ \\
\hline The insignificant effects of proper documentation on nurses' career advancement & $4.20 \pm 1.42$ & $3.83 \pm 0.98$ \\
\hline
\end{tabular}

Table 3. Comparison of Head Nurses' and Nurses' Perspectives on the Factors Behind the Quality of Nursing Documentation

\begin{tabular}{lcc}
\hline Factors & Head Nurses (Mean \pm SD) & Nurses (Mean \pm SD) \\
\hline Personal & $3.49 \pm 0.91$ & $3.51 \pm 0.79$ \\
Managerial & $3.84 \pm 1.18$ & $3.70 \pm 0.67$ \\
Organizational & $4.01 \pm 0.62$ & $3.99 \pm 0.52$ \\
Pvalue $^{\mathbf{b}}$ & 0.28 & 0.49 \\
\hline
\end{tabular}

${ }^{\mathrm{a}}$ The results of Mann-Whitney $\mathrm{U}$ test.

${ }^{\mathrm{b}}$ The results of the Friedman test. 


\section{Acknowledgments}

This study was approved and funded by the Birjand University of Medical Sciences, Birjand, Iran. We would like to thank the Research Administration of the University, as well as the nurses and managers of Valiasr (PBUH) Hospital, Birjand, Iran.

\section{Footnotes}

Conflict of Interests: The authors declare that there are no conflict of interests.

\section{Ethical Considerations: IR.BUMS.REC.13960221.}

\section{References}

1. Hanifi N, Mohamadi E. [Survey of causes of faculty nursing documentation]. Hayat. 2004;10(2):39-46. Persian.

2. Stevens S, Pickering D. Keeping good nursing records: A guide. Community Eye Hlth. 2010;23(74):44-5. [PubMed: 21311663]. [PubMed Central: PMC3033612].

3. Ammenwerth E, Mansmann U, Iller C, Eichstadter R. Factors affecting and affected by user acceptance of computer-based nursing documentation: Results of a two-year study. J Am Med Inform Assoc. 2003;10(1):69-84. [PubMed: 12509358]. [PubMed Central: PMC150360].

4. Meissner A, Schnepp W. Staff experiences within the implementation of computer-based nursing records in residential aged care facilities: A systematic review and synthesis of qualitative research. BMC Med Inform Decis Mak. 2014;14:54. doi: 10.1186/1472-6947-14-54. [PubMed: 24947420]. [PubMed Central: PMC4114165].

5. Kahouei M, Baba Mohammadi H, Askari Majdabadi H, Solhi M, Parsania Z, Said Roghani P, et al. Nurses' perceptions of usefulness of nursing information system: Module of electronic medical record for patient care in two university hospitals of iran. Mater Sociomed. 2014;26(1):30-4. doi: 10.5455/msm.2014.26.30-34. [PubMed: 24757398] [PubMed Central: PMC3990381].

6. Ahmadi M, Rafii F, Hoseini F, Koolaee HM, Mirkarimi A. [Informational and structural needs of nursing data classification in computerized systems]. Hayat. 2011;17(1). Persian.

7. Wang N, Hailey D, Yu P. Quality of nursing documentation and approaches to its evaluation: A mixed-method systematic review. J Adv Nurs. 2011;67(9):1858-75. doi: 10.1111/j.1365-2648.2011.05634.x. [PubMed: 21466578].
8. Johnson MK, Symes L, Bernard L, Landson MJ, Carroll TL. Mentoring disadvantaged nursing students through technical writing workshops. Nurse Educ. 2007;32(4):168-72. doi: 10.1097/01.NNE.0000281087.43088.f5. [PubMed: 17627209].

9. Cheevakasemsook A, Chapman Y, Francis K, Davies C. The study of nursing documentation complexities. Int J Nurs Pract. 2006;12(6):36674. doi: 10.1111/j.1440-172X.2006.00596.x. [PubMed: 17176310].

10. Mohammad Ghasaby M, Masudi Alavi N. [Quality and barriers against nursing documentation in Kashan Shahid Beheshti Hospital (2011)]. Mod Care J. 2012;9(4):336-43. Persian.

11. Harkeader H. Textbook of fundamentalof nursing care: A clinical judgment. Philadelphia: W.B Saunders Company; 2000.

12. Howse E, Bailey J. Resistance to documentation-a nursing research issue. Int J Nurs Stud. 1992;29(4):371-80. [PubMed: 1428602].

13. Matboee M, Mohammadi E, Zargarzadeh M. [Assessment of barriers for recording nursing diagnoses by nurses and proposing a solution]. Adv Nurs Midwifery. 2013;23(83):27-33. Persian.

14. Clarke SP, Donaldson NE. Nurse staffing and patient care quality and safety. In: Hughes RG, editor. Patient safety and quality: An evidencebased handbook for nurses. Rockville (MD): Agency for Healthcare Research and Quality (US); 2008.

15. Atashzadeh SF, Ashktorab T. Factors influencing implementation of nursing process by nurses: A qualitative study. Knowl Health. 2011;6(3):16-23.

16. Kahouei M, Sadoughi F, Askari Majdabadi H. [Medical assistant's and students knowledge and practice rate of Semnan University of Medical Sciences regarding to documentation of care provided to patient from medico legal aspect]. J Legal Med Islam Repub Iran. 2007;46(13):92-7. Persian.

17. Farzi S, Moladoost A. [Quality of nursing records and its relationship with some demographic characteristics of nurses working in intensive care units]. Iran J Nurs Res. 2016;11(2):24-31. Persian.

18. Tapp RA. Inhibitors and facilitators to documentation of nursing practice. West J Nurs Res. 1990;12(2):229-40. doi: 10.1177/019394599001200208. [PubMed: 2321376].

19. Uys LR, Minnaar A, Simpson B, Reid S. The effect of two models of supervision on selected outcomes. J Nurs Scholarsh. 2005;37(3):282-8. [PubMed: 16235871]

20. Rozitalab M, Azimi S, Mobaraaki A, Mohebbi Z. [The quality of recording the nursing report in Emam Sajad and Beheshti Hospital Yasouj, 2006]. Dena Q Yasuj Faculty Nurs Midwifery. 2007;2(3):61-71. Persian.

21. Ghazanfari Z,Sheykhpour-Khani M,Haghdoost A. [Nurse's knowledge and practice of the principles of nursing documentation at hospitals of Kerman University of Medical Sciences]. Iran Nurs J.2008;22(59):1622. Persian. 